\title{
Stochastic Framework for Strategic Decision-making of Load-serving Entities for Day-ahead Market
}

\author{
Mohammad Ali Fotouhi Ghazvini, Pedro Faria, Hugo Morais, Zita Vale, Sérgio Ramos \\ GECAD - Knowledge Engineering and Decision Support Research Center \\ IPP - Polytechnic of Porto \\ Porto, Portugal \\ mafgh@isep.ipp.pt, pnfar@isep.ipp.pt, hugvm@isep.ipp.pt, zav@isep.ipp.pt, scr@isep.ipp.pt
}

\begin{abstract}
The deregulation of electricity markets has diversified the range of financial transaction modes between independent system operator (ISO), generation companies (GENCO) and load-serving entities (LSE) as the main interacting players of a day-ahead market (DAM). LSEs sell electricity to end-users and retail customers. The LSE that owns distributed generation (DG) or energy storage units can supply part of its serving loads when the nodal price of electricity rises. This opportunity stimulates them to have storage or generation facilities at the buses with higher locational marginal prices (LMP). The short-term advantage of this model is reducing the risk of financial losses for LSEs in DAMs and its long-term benefit for the LSEs and the whole system is market power mitigation by virtually increasing the price elasticity of demand. This model also enables the LSEs to manage the financial risks with a stochastic programming framework.
\end{abstract} Index Terms- Demand-side, load-serving entities, locational
marginal price, market power, stochastic programming. marginal price, market power, stochastic programming.

\section{NOMENCLATURE}

\section{Indices:}

j LSEs.

$t \quad$ Hours.

$s \quad$ Scenarios.

$b \quad$ Buses.

c Consumers.

$i \quad$ DG units.

$k \quad$ Storage units.

Parameters:

$L M P_{b} \quad$ Locational marginal price at bus $b(€ / \mathrm{MWh})$.

$R_{c} \quad$ Utility rate that the consumer $c$ is charged by the

LSE for electrical energy consumption ( $€ / \mathrm{MWh})$.

$N_{s} \quad$ Number of scenarios.

$\omega_{s} \quad$ Weight of scenario $s$.

$C_{i}^{F} \quad$ Fixed cost of DG $i(€ / \mathrm{h})$.

$C_{i}^{P} \quad$ Production cost of DG $i(€ / \mathrm{MWh})$.

This work is supported by FEDER Funds through "Programa Operacional Factores de Competitividade - COMPETE" program and by National Funds through FCT "Fundação para a Ciência e a Tecnologia" under the projects FCOMP-01-0124-FEDER: PEst-OE/EEI/UI0760/2011, PTDC/EEA-EEL/099832/2008, and PTDC/SEN-ENR/122174/2010.

\begin{tabular}{|c|c|}
\hline$C_{i}^{\text {start }}$ & Start-up cost of DG $i(€)$. \\
\hline$E_{k}^{\mathrm{Max} / \mathrm{Min}}$ & $\begin{array}{l}\text { Maximum/minimum storage level of storage unit } \\
k(\mathrm{MWh}) \text {. }\end{array}$ \\
\hline$G_{i}^{\mathrm{Max} / \mathrm{Min}}$ & $\begin{array}{l}\text { Maximum/minimum power generation of DG } i \\
\text { (MW). }\end{array}$ \\
\hline$\eta_{k}^{\mathrm{IN} / \mathrm{OUT}}$ & Charging/discharging efficiency of storage unit $k$. \\
\hline$R_{k}^{\mathrm{IN} / \mathrm{OUT}}$ & $\begin{array}{l}\text { Charging/discharging rate of storage unit } k \\
(\mathrm{MW} / \mathrm{h}) \text {. }\end{array}$ \\
\hline$l_{c}$ & $\begin{array}{l}\text { Real energy consumption forecast for consumer } c \\
(\mathrm{MWh}) .\end{array}$ \\
\hline$T$ & Number of time periods. \\
\hline \multicolumn{2}{|l|}{ Variables: } \\
\hline$P_{j}^{D+1}$ & Expected payoff of LSE $j$ in the DAM $(€)$. \\
\hline$g_{i}$ & Real power generation of DG $i$ (MWh). \\
\hline$p_{k}^{\mathrm{IN} / \mathrm{OUT}}$ & $\begin{array}{l}\text { Charging/discharging power of storage unit } k \\
(\mathrm{MW} / \mathrm{h}) \text {. }\end{array}$ \\
\hline$E_{k}^{\text {stored }}$ & $\begin{array}{l}\text { Energy storage level of storage unit } k \text { at the end } \\
\text { of each time period }(\mathrm{MWh}) \text {. }\end{array}$ \\
\hline$d_{b}$ & $\begin{array}{l}\text { Amount of energy that is bought from the } \\
\text { wholesale market by the LSE (MWh). }\end{array}$ \\
\hline$u_{i}$ & $\begin{array}{l}\text { Binary decision variable showing the } \\
\text { commitment status of DG unit } i \text { ( } 1 \text { if the unit is } \\
\text { online and } 0 \text { otherwise). }\end{array}$ \\
\hline$v_{i}$ & $\begin{array}{l}\text { Binary decision variable for start-up status of } \mathrm{DG} \\
i \text { ( } 1 \text { if the unit starts up at the beginning of period } \\
t \text { and } 0 \text { otherwise). }\end{array}$ \\
\hline$w_{i}$ & $\begin{array}{l}\text { Binary decision variable for shut-down status of } \\
\text { DG } i \text { ( } 1 \text { if the unit shuts down at the beginning of } \\
\text { period } t \text { and } 0 \text { otherwise). }\end{array}$ \\
\hline$x_{k}$ & $\begin{array}{l}\text { Binary decision variable for discharging status of } \\
\text { storage unit } k \text { ( } 1 \text { if it is discharging and } 0 \\
\text { otherwise). }\end{array}$ \\
\hline$y_{k}$ & $\begin{array}{l}\text { Binary decision variable for charging status of } \\
\text { storage unit } k \text { ( } 1 \text { if it is charging and } 0 \\
\text { otherwise). }\end{array}$ \\
\hline
\end{tabular}

$C_{i}^{\text {start }}$

$G_{i}$

$\eta_{k}^{\mathrm{IN} / \mathrm{OUT}}$

$R_{k}^{\mathrm{IN} / \mathrm{OUT}}$

1 $P$ 
Sets:

$\Omega_{j} \quad$ Buses that the LSE $j$ is serving loads in them or possesses DGs or storage units in them.

$\Omega_{j}^{b-c}$

$\Omega_{j}^{b-D G}$

$\Omega_{j}^{b-E S S}$ Consumers served by LSE $j$ at bus $b$.

DGs owned by LSE $j$ at bus $b$. storage units owned by LSE $j$ at bus $b$.

\section{INTRODUCTION}

The welfare of LSEs is the profit achieved from reselling the purchased power at wholesale markets to retail customers [1]. Retail end-users do not receive signals from the changes in the electricity price, and almost never react to the short-term price rises. Although the two-sided auction structure of wholesale markets provides the potentials for electricity buyers to neutralize the market power [2], the willingness of retail customers in paying regulated electricity rates without being influenced by hourly wholesale LMPs is a barrier for this purpose.

The LSEs buy bulk power from DAM at volatile market prices and sell at fixed prices. They face uncertainty and risky operation like other players of electricity markets, but their risk for financial losses is higher than other participants. In this paper, we aim to model a framework that limits the potential for market power and assists the LSEs in financial risk management during DAM.

The proposed stochastic framework gives LSEs the possibility of managing the financial risks by considering the impact of uncertain loads and market prices. It is also assumed that these LSEs possess several DGs and storage units to limit the potential for market power by submitting more price elastic demand bids. The suppliers cannot significantly increase the price above their actual costs, and by repeatedly playing in this market, they will learn over time to compete less aggressively [3].

Demand biding of LSEs in a DAM with a non-profit ISO and price-sensitive demand-side is studied in [1]. It has been proved that in absence of active demand-side bidding, the suppliers have the potential for market power and can push up the prices [2]. Simulation results in [3] show how the GENCOs facilitated by Q-learning can exploit the market flaws and achieve higher profits relative to the competitive benchmark in the absence of market power mitigation strategies. The problem of energy trading for a LSE that owns generating units and coordinates the vehicle-to-grid services is formulated as a mixed-integer stochastic linear program in [4]. The LSE in this model also acts as an electric vehicle aggregator. Bilateral contracts between the GENCOs and the LSEs have been investigated in [5-7] as a means to manage and limit the financial risks of both sides. Strategic bidding of GENCOs, facing an inelastic load in a DAM with a singlesided uniform price auction is modeled in [8].

We have made the following contributions in our proposed model compared to the state of the art: (i) The LSEs manage their financial risks with a stochastic programming model. (ii) $\mathrm{K}$-means clustering is used to partition the scenarios and reduce the size of the stochastic problem. (iii) The expected increase in the payoff of LSEs when they use DGs or the storage units to supply their loads and submit more price elastic demand bids is analyzed through a case study.

The DAM operations and the market power experience in this environment are introduced in section III. In section IV, the reasons for LSEs' financial risks are described. The stochastic programming model in section $\mathrm{V}$ is applied on a test system in section VI. The final section is assigned to the conclusions and the future works.

\section{DAY-AHEAD MARKET OPERATIONS}

The LSE obtain the electrical energy needs of the end users from forward market, day-ahead market, real-time market and the bilateral contracts with GENCOs [7, 9]. It sells electricity and other ancillary services that are provided from the wholesale market to the end-users in a retail market [10, 11]. Although in real-world markets a large part of electricity consumption is traded through long-term contracts, DAM keeps gaining importance because of its role in determining the long-run electricity costs [12]. In a DAM the LMPs are determined based on a security-constrained optimal power flow, considering the limitations of the generation sector and the load specifications.

The LSEs procure the day-ahead capacity on wholesale markets, even so the consumptions of the retail customers should be adapted in real time [10]. The ISO/Market Operator of a deregulated electricity market matches sellers' quantityprice supply offers and buyers' demand bids for day-ahead power exchange with an auction based mechanism [8]. The bidding strategies are affected with the auction rules, protocols and the electricity market structure [8]. The bidders submit the bids to the ISO/Market Operator without knowledge of the submitted bids of other market participants. The auction also runs in one round and the participants do not have the opportunity of receiving any feedback on their agents' bidding behavior [12].

Fig. 1 shows the procedure of bidding and market clearance in a DAM. One day prior to the start of a DAM, load prediction data is gathered from LSEs and the ISO publishes the forecasted zonal load data for the following day [3]. The hourly demand bid of LSEs includes an inverse demand function, showing the willingness to pay for each MWh based on anticipations of the energy consumption of the end-users with variable-price retail contracts and a fixed load level for customers with fixed-price retail contracts $[1,5]$. The demand functions are obtained after curve-fitting different prices for each year and the corresponding optimal energy usages. Once the demand function of each individual consumer is determined, the LSE can aggregate them to obtain the demand bid [13]. The ISO builds the demand and supply function after aggregating the submitted curves of market players [12].

The specific features of deregulated electricity markets, i.e., open competition; unbundling electricity services and open access to the network allow the GENCOs to experience market power by tendering optimal offers [8]. Market power causes price rise in DAM when the few firms that own most of the generation capacity unilaterally alter the prices away from 
the competitive levels [14]. More elastic demand bids in a DAM can limit the risk of market power. A great proportion of ongoing debates on electricity market design are focused on designing the market power mitigation rules [6].

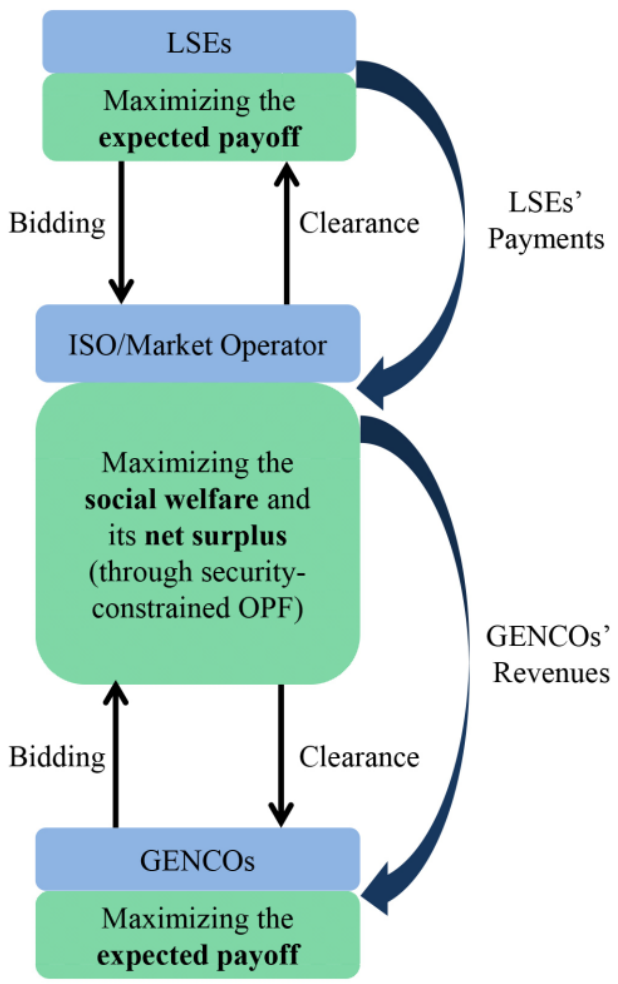

Figure 1. Bidding and clearnace procedure in a DAM [1]

\section{FINANCIAL RISKS OF LSES}

Financial risks often indicate downside risks in a market, meaning the uncertainty of a payoff and the potential for financial loss [15]. The LSEs sell the electricity at fixed prices, but their return is uncertain in DAM [16]. The LSEs participating in the electricity markets face risks due to volatility of the pool prices and the loads energy consumption [6]. In DAMs the MCP can be estimated with a high uncertainty and the LSEs are directed to base their planning on the estimated MCPs in order to achieve higher incomes. The LSE also faces the volume risk for the optimal resource and load scheduling, because the amount that each customer will use in a day-ahead cannot be forecasted with high accuracy.

The contracts of retail customers with the LSEs shield them from even the smallest price fluctuations in short-term perspective, and the LSE has to face the financial risks of wholesale market [7]. However, the profit-seeking LSEs of competitive electricity markets should accordingly react to system conditions to gain more financial payoff or avoid the financial loss.

Buying electricity at a fixed price through forward contracts allows LSEs to hedge against the risks of price variability [6]. Involving in hedge contracts with the producers is an option for LSEs to overcome the high risk of attending the auction for the loads that buy electricity at a regulated rate.
The uncertainty of parameters plays an important role when the financial scheduling is based on future events [16]. The stochastic programming is used in this model to manage the financial risks of LSEs in DAMs by allowing the uncertainty to be taken into account [16]. It is implemented in this model to characterize the strategies of a risk-averse LSE to avoid financial losses. A big assumption in stochastic programming is that the probability distributions of random parameters are known [16]. The main challenge in stochastic programming is the size of the model that will be dealt with by reducing the number of scenarios.

\section{PROBLEM FORMULATION}

\section{A. Stochastic model}

The goal of this model is to precisely characterize how the LSEs that own DGs/storage units obtain the optimal demand bid. During day D, the LSEs submit their demand bids that include a 24-hour load profile at the buses that they serve loads. The retail customers will pay LSEs a regulated rate $(€ / \mathrm{MWh})$ for each hour. But at the end of day D, the LSEs are charged the market clearing price for each bus at time period $t$ $\left(L M P_{b}(t)\right)$. The deviation between cleared demand and actual demand is resolved in the real-time balancing markets. The market operator or the ISO determines the market clearing price at each bus through running optimal power flow [5].

The objective of the LSE is to obtain the optimal demand bid that ensures the maximum payoff for them. The LSE controls the output of the storage units/DGs to gain higher profit. The optimal demand bids are determined with regard to the optimal schedules of the commitment and generation of the DGS/storage units owned by the LSEs. Suppliers and customers submit hourly supply and demand bids to the ISO. The hourly market clearing price and the cleared energy volume of each participant is determined for the following day by the ISO after intersecting the aggregated supply and demand bids [4].

Several plausible scenarios with their assigned probabilities represent the stochastic processes and the uncertain variables in the stochastic programming model. The uncertainty of LMPs is a notable determinant for the LSEs' scheduling procedure, due to its significant influence on the total payoff. LMPs at each bus depend on the price elasticity of the loads being supplied at that node. The objective of the LSE is to maximize its expected payoff (1) in the DAM.

$$
\begin{aligned}
P_{j}^{D+1}= & \sum_{s=1}^{N_{s}} \omega_{s} \cdot \sum_{b \in \Omega_{j}} \sum_{t=1}^{24}\left[\sum_{c \in \Omega_{j}^{b-c}} R_{c}(t) \cdot l_{c}^{s}(t)-L M P_{b}^{s}(t) \cdot d_{b}^{s}(t)\right. \\
& -\sum_{i \in \Omega_{j}^{b-D G}}\left(C_{i}^{F} \cdot u_{i}^{s}(t)+C_{i}^{P}(t) \cdot g_{i}^{s}(t)+C_{i}^{\text {Start }} \cdot v_{i}^{s}(t)\right) \\
& \left.-\sum_{k \in \Omega_{j}^{b-E S S}}\left(P_{k}^{\mathrm{in}, s}(t) \cdot L M P_{b}^{s}(t)\right)\right]
\end{aligned}
$$

LSE $j$ procures the loads with the energy bought in the wholesale market and uses the storage units/DGs that are owned or managed by it (2) [17]. It needs the schedules of its 
storage units/DGs to determine the optimal demand bid to submit to the ISO.

$$
\sum_{c \in \Omega_{j}^{b-c}} l_{c}^{s}(t)=d_{b}^{s}(t)+\sum_{i \in \Omega_{j}^{b-D G}} g_{i}^{s}(t)+\sum_{k \in \Omega_{j}^{b-E S S}} p_{k}^{\mathrm{OUT}, s}(t) \quad \forall s, t, b .
$$

The generation of each DG should be within the range of minimum power generation and the capacity of the DG (3). The logic between the start-up, shut-down and the commitment of the DG units is shown in (4) and (5), and DG starts up or shuts down once during each time period (6).

$$
\begin{array}{cc}
G_{i}^{\mathrm{Min}} \cdot u_{i}^{s}(t) \leq g_{i}^{s}(\mathrm{t}) \leq G_{i}^{\mathrm{Max}} \cdot u_{i}^{s}(t) & \forall s, i, t . \\
v_{i}^{s}(t)-w_{i}^{s}(t)=u_{i}^{s}(t)-u_{i}^{s}(t-1) & \forall s, i, t=2, \ldots, T . \\
v_{i}^{s}(t)-w_{i}^{s}(t)=u_{i}^{s}(t)-u_{i}^{\text {initial }} & \forall s, i, t=1 . \\
v_{i}^{s}(t)+w_{i}^{s}(t) \leq 1 & \forall s, i, t .
\end{array}
$$

The energy storage level at the end of each time period depends on the storage level of the beginning of the time period in addition to the charging and discharging hourly power (7) [18]. The effect of initial energy storage level of storage units for the first time period is characterized in (8). The level of storage in each storage unit is within a certain range represented by its minimum allowed storage and the capacity (9).

$$
\begin{aligned}
& E_{K}^{\mathrm{stored}, s}(t)=\eta_{k}^{\mathrm{IN}} \cdot p_{k}^{\mathrm{IN}, s}(t)-1 / \eta_{k}^{\text {OUT }} \cdot p_{k}^{\mathrm{OUT}, s}(t) \\
& +E_{k}^{\text {stored,s }}(t-1) \quad \forall s, k, t=2, \ldots, T . \\
& E_{K}^{\mathrm{stored}, s}(t)=\eta_{k}^{\mathrm{IN}} \cdot p_{k}^{\mathrm{IN}, s}(t)-1 / \eta_{k}^{\mathrm{OUT}} \cdot p_{k}^{\mathrm{OUT}, s}(t) \\
& +E_{k}^{\text {initial }} \quad \forall s, k, t=1 . \\
& E_{k}^{\mathrm{Min}} \leq E_{k}^{\text {stored,s }}(t) \leq E_{k}^{\mathrm{Max}} \quad \forall s, t, k .
\end{aligned}
$$

The storage units are scheduled to just charge or discharge during each period (10). The constraints (11) and (12) establish an additional limitation on the operation of storage units that the charge and discharge rate should also be within the nominal rates.

$$
\begin{array}{cc}
x_{k}^{s}(t)+y_{k}^{s}(t) \leq 1 & \forall s, k, t . \\
1 / \eta_{k}^{\text {OUT }} \cdot p_{k}^{\text {OUT }, s}(t) \leq R_{k}^{\mathrm{OUT}} \cdot x_{k}^{s}(t) & \forall s, t, k . \\
\eta_{k}^{\mathrm{IN}} \cdot p_{k}^{\mathrm{IN}, s}(t) \leq R_{k}^{\mathrm{IN}} \cdot y_{k}^{s}(t) & \forall s, t, k .
\end{array}
$$

\section{B. Scenarios}

The uncertainty of the input data in a stochastic programming model is introduced with a set of scenarios. The selection of these scenarios is an important task that profoundly impacts the procedure of decision making. If the number of scenarios is large and the input data is not processed before implementation, the size of the problem and the time needed for the execution of the optimization problem can be a great challenge for decision-makers.

In this paper, scenarios are generated from the historical data and the K-means clustering technique is used to reduce the data set by grouping similar scenarios. The number of observations in each group gives the probability of occurrence for these scenarios [19].

Historical data have been used for the price and load data. In order to achieve a tractable data set from the original information, the K-means clustering algorithm iteratively computes the distance between each scenario and the cluster centroid [20]. The number of clusters should be firstly set for the algorithm.

\section{NUMERICAL RESULTS}

The proposed model is tested on the modified IEEE 24-bus test system (Figure 2) [21] to assess its applicability and performance in financial risk management of LSEs. As shown in the test system, 5 LSEs are participating in the DAM as load aggregators. There are also a few loads that directly enter the market independent of the LSEs. The LSEs own several storage units/DGs at the nodes that they are serving the retail customers (Tables I and II). The LSEs use these sources to reduce the risk of financial loss and submit more price elastic demand bids to the ISO/market operator.

Each LSE supply one or more customer groups at each node. The LSEs have offered specified fixed or hourly variable tariffs for electricity consumption to the retail customers. The tariffs of the customer groups depend on the type of the contracts signed with the LSEs. The electricity consumption tariffs for each customer group are shown in Figure 3 . The red lines in this figure show the maximum and minimum amount of the regulated rates.

It is assumed that the LSEs have considered 100 different hourly LMP realizations for each bus with equal probability of occurrence. The number of scenarios is then reduced to 10 clusters for each LSE with the K-means clustering technique. The hourly average of LMPs in each cluster represents the LMP profile for that scenario, and the number of scenarios assigned to each cluster relative to the number of total scenarios gives the weight for that scenario.

All the mixed integer optimization problems of LSEs are implemented in GAMS [22] and solved with the CPLEX 11.2.0 solver. The expected profits of LSEs in both cases show how the LSEs are expecting more payoffs by using their own DGs or storage units (Table III).

LSE 2 expects $1274.8 €$ of profit instead of expecting $714.5 €$ of financial loss in the DAM by considering its DGs or storage units and changing the demand bids that it is submitting for the DAM. Other LSEs also expect more payoffs by using their DGs or storage units. In Figure 4 the difference between the forecasted demand and the demand bids that the LSEs are submitting to the DAM is illustrated. 
TABLE I. SPECIFICATION OF THE STORAGE UNITS OWNED BY LSES.

\begin{tabular}{ccccccccc}
\hline $\begin{array}{c}\text { Storage } \\
\text { Units }\end{array}$ & $\begin{array}{c}\text { Charging } \\
\text { Efficiency }\end{array}$ & $\begin{array}{c}\text { Discharging } \\
\text { Efficiency }\end{array}$ & $\begin{array}{c}\text { Capacity } \\
(\mathbf{M W h})\end{array}$ & $\begin{array}{c}\text { Minimum Energy } \\
\text { Level (MWh) }\end{array}$ & $\begin{array}{c}\text { Charging Rate } \\
(\mathbf{M W} / \mathbf{h})\end{array}$ & $\begin{array}{c}\text { Discharging } \\
\text { Rate (MW/h) }\end{array}$ & LSE & Bus \\
\hline \hline $\mathbf{1}$ & 0.95 & 0.88 & 19.80 & 4.00 & 3.50 & 7.00 & 1 \\
\hline $\mathbf{2}$ & 1.00 & 0.92 & 16.50 & 0.85 & 4.00 & 5.50 & 4 \\
\hline $\mathbf{3}$ & 0.79 & 0.91 & 9.00 & 2.50 & 2.00 & 3.50 & 1 \\
\hline $\mathbf{4}$ & 0.89 & 0.65 & 14.00 & 5.00 & 6.00 & 6.30 & 1 & 24 \\
\hline $\mathbf{5}$ & 0.87 & 0.93 & 32.00 & 3.70 & 6.25 & 9.50 & 2 & 20 \\
\hline $\mathbf{6}$ & 0.85 & 0.90 & 11.00 & 2.00 & 2.50 & 3.00 & 3 \\
\hline $\mathbf{7}$ & 0.75 & 0.85 & 6.50 & 4.00 & 4.30 & 1.90 & 3 \\
\hline $\mathbf{8}$ & 0.90 & 0.78 & 5.00 & 0.50 & 2.00 & 3.25 & 3 \\
\hline $\mathbf{9}$ & 0.85 & 0.90 & 11.00 & 2.00 & 2.50 & 3.00 & 4 & 24 \\
\hline $\mathbf{1 0}$ & 0.80 & 0.96 & 13.00 & 2.00 & 2.90 & 3.65 & 5 & 7 \\
\hline
\end{tabular}

TABLE II. SPECIFICATION OF THE DGS OWNED BY LSES.

\begin{tabular}{|c|c|c|c|c|c|c|c|}
\hline DGs & $\begin{array}{c}\text { Fixed Cost } \\
(€ / h)\end{array}$ & $\begin{array}{c}\text { Production Cost } \\
(€ / M W h)\end{array}$ & $\begin{array}{c}\text { Start-up Cost } \\
(€)\end{array}$ & Capacity (MW) & $\begin{array}{c}\text { Minimum } \\
\text { Power (MW) } \\
\end{array}$ & LSE & Bus \\
\hline 1 & 113.00 & 43.00 & 7.00 & 11.00 & 20 & 1 & 3 \\
\hline 2 & 87.00 & 51.00 & 11.00 & 17.00 & 2.00 & 1 & 5 \\
\hline 3 & 139.00 & 38.00 & 9.00 & 28.00 & 3.00 & 1 & 15 \\
\hline 4 & 93.45 & 62.00 & 24.00 & 12.00 & 2.50 & 2 & 14 \\
\hline 5 & 101.00 & 53.50 & 43.50 & 30.85 & 6.00 & 2 & 20 \\
\hline 6 & 93.00 & 39.00 & 12.00 & 5.00 & 0.60 & 3 & 3 \\
\hline 7 & 182.00 & 51.00 & 21.00 & 3.00 & 0.45 & 3 & 3 \\
\hline 8 & 60.00 & 36.00 & 45.00 & 3.30 & 0.25 & 3 & 11 \\
\hline 9 & 85.00 & 47.00 & 12.60 & 6.20 & 0.30 & 3 & 24 \\
\hline 10 & 93.00 & 45.00 & 36.00 & 4.00 & 0.60 & 4 & 22 \\
\hline 11 & 96.60 & 39.50 & 16.00 & 0.80 & 0.00 & 5 & 6 \\
\hline 12 & 103.00 & 56.00 & 21.00 & 2.63 & 0.45 & 5 & 6 \\
\hline 13 & 88.00 & 51.00 & 45.00 & 6.00 & 1.50 & 5 & 7 \\
\hline 14 & 111.00 & 43.90 & 39.00 & 2.20 & 0.30 & 5 & 7 \\
\hline
\end{tabular}

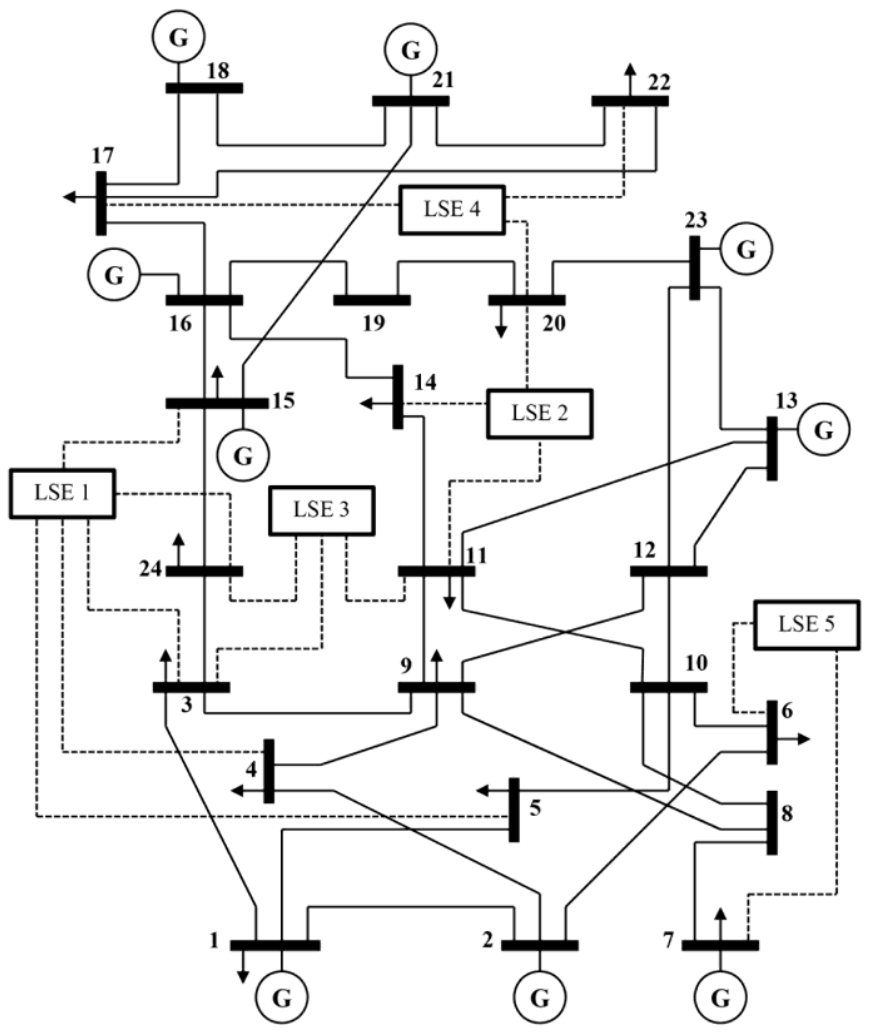

Figure 2. IEEE 24-bus test system.

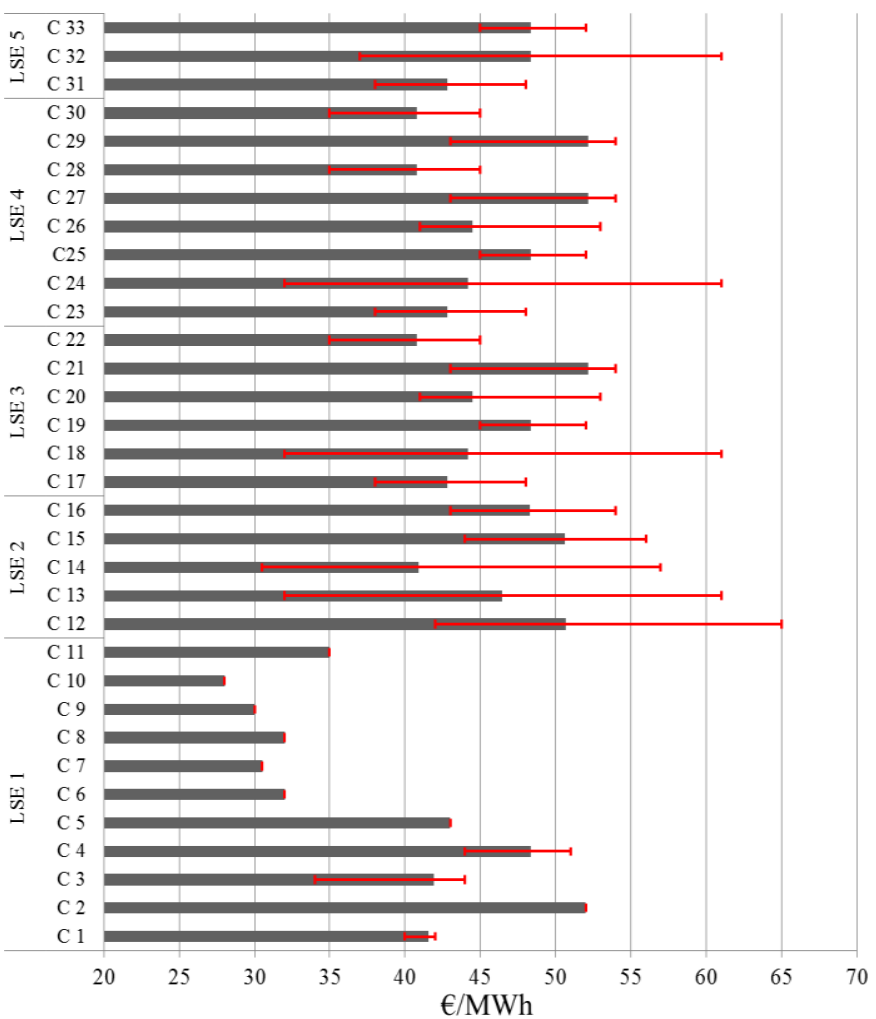

Figure 3. Regulated electricity rates for the customer groups. 
TABLE III. EXPECTED PAYOFF OF LSES.

\begin{tabular}{lcc}
\hline & $\begin{array}{c}\text { Without DGs/storage } \\
\text { units }(\boldsymbol{\epsilon})\end{array}$ & $\begin{array}{c}\text { With DGs/storage } \\
\text { units }(\boldsymbol{\epsilon})\end{array}$ \\
\hline \hline LSE 1 & 2852.0 & 3790.2 \\
\hline LSE 2 & -714.5 & 1274.8 \\
\hline LSE 3 & 4340.7 & 4866.5 \\
\hline LSE 4 & 187.5 & 282.5 \\
\hline LSE 5 & 777.9 & 1078.2 \\
\hline
\end{tabular}

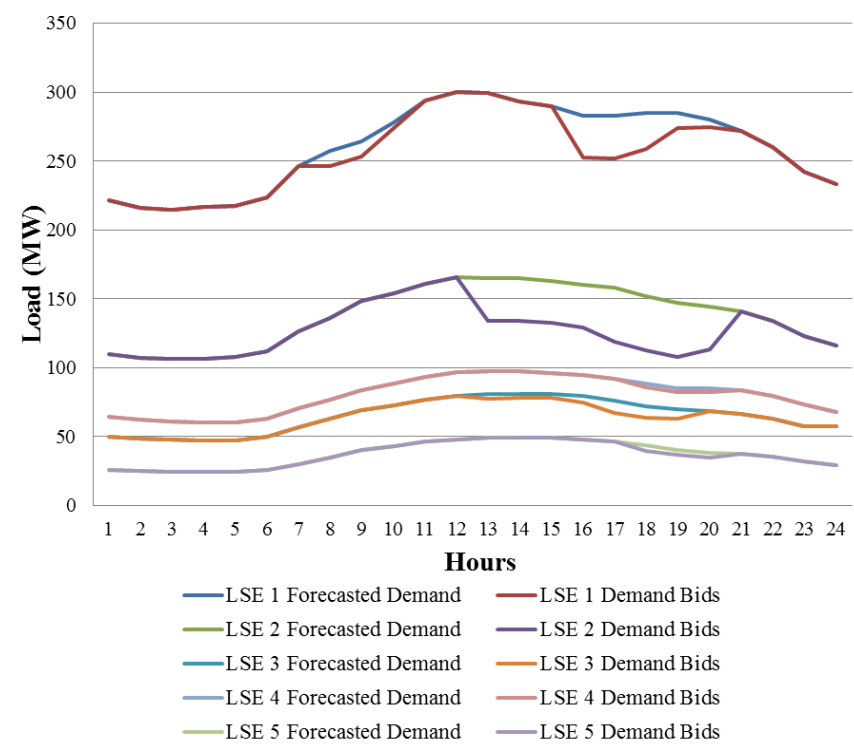

Figure 4. The forecasted demand and the demand bids of LSEs in DAM

\section{CONCLUSION}

The LSEs at any level of participation in the electricity market are encouraged to supply their loads with their storage units or DG units when prices rise. Through this mechanism, they can increase the price elasticity of the demand that they are submitting to the ISO for the DAM and reduce the risk of market power for GENCOs. The advantage of this mechanism in reducing the risk of financial loss in a short-term horizon is analyzed in this paper. If the LSEs expect higher LMPs during peak load periods, they will partially supply their loads with their own sources and consequently the total peak consumption reduces.

In our proposed model, the LSE owns several storage units/DGs and the scheduling of these sources for the optimal operation is its main issue before entering the DAM. Besides this, we are going one step forward in our future works by shifting the problem to calculating the storage units/DGs optimal rating in order to reduce the financial risks of LSEs in a long-term horizon.

\section{REFERENCES}

[1] L. Hongyan and L. Tesfatsion, "ISO Net Surplus Collection and Allocation in Wholesale Power Markets Under LMP," Power Systems, IEEE Transactions on, vol. 26, pp. 627-641, 2011.
[2] S. J. Rassenti, V. L. Smith, and B. J. Wilson, "Demand-side bidding will control market power, and decrease the level and volatility of prices," Economic Science Laboratory, University of Arizona2001.

[3] Y. Nan-Peng, L. Chen-Ching, and J. Price, "Evaluation of Market Rules Using a Multi-Agent System Method," Power Systems, IEEE Transactions on, vol. 25, pp. 470-479, 2010.

[4] A. T. Al-Awami and E. Sortomme, "Coordinating Vehicle-to-Grid Services With Energy Trading," Smart Grid, IEEE Transactions on, vol. 3, pp. 453-462, 2012.

[5] Y. Nanpeng, L. Tesfatsion, and L. Chen-Ching, "Financial Bilateral Contract Negotiation in Wholesale Electricity Markets Using Nash Bargaining Theory," Power Systems, IEEE Transactions on, vol. 27, pp. 251-267, 2012.

[6] S. Pineda and A. J. Conejo, "Managing the financial risks of electricity producers using options," Energy Economics, vol. 34, pp. 2216-2227, 2012.

[7] R. C. Leou and J. H. Teng, "The optimal portfolio of the day-ahead market and real-time market for the load serving entities," in Industrial Informatics (INDIN), 8th IEEE International Conference on, 2010, pp. 804-809.

[8] G. Li and J. Shi, "Agent-based modeling for trading wind power with uncertainty in the day-ahead wholesale electricity markets of singlesided auctions," Applied Energy, vol. 99, pp. 13-22, 2012.

[9] Z. Vale, T. Pinto, I. Praça, and H. Morais, "MASCEM: Electricity Markets Simulation with Strategic Agents," Intelligent Systems, IEEE, vol. 26, pp. 9-17, 2011

[10] J. Libin and S. Low, "Multi-period optimal energy procurement and demand response in smart grid with uncertain supply," in Decision and Control and European Control Conference (CDC-ECC), 50th IEEE Conference on, 2011, pp. 4348-4353.

[11] H. M. Ghadikolaei, E. Tajik, J. Aghaei, and M. Charwand, "Integrated day-ahead and hour-ahead operation model of discos in retail electricity markets considering DGs and CO2 emission penalty cost," Applied Energy, vol. 95, pp. 174-185, 2012.

[12] N. S. María, "Day-ahead electricity market: proposals to adapt complex conditions in OMEL," M.Sc. thesis, ICAI School of Engineering, Comillas Pontifical University, Madrid, 2010.

[13] J.-Y. Joo and M. D. Ilic, "A multi-layered adaptive load management (ALM) system: Information exchange between market participants for efficient and reliable energy use," in Transmission and Distribution Conference and Exposition, IEEE PES, 2010, pp. 1-7.

[14] U. K. Shukla and A. Thampy, "Analysis of competition and market power in the wholesale electricity market in India," Energy Policy, vol. 39, pp. 2699-2710, 2011.

[15] A. J. McNeil, R. Frey, and P. Embrechts, Quantitative risk management: concepts, techniques, and tools: Princeton university press, 2005.

[16] X. Yang, "Applying Stochastic Programming Models in Financial Risk Management," Ph. D. dissertation, Univ. Edinburgh, Edinburgh, UK, 2009.

[17] M. A. Fotouhi Ghazvini, H. Morais, and Z. Vale, "Coordination between mid-term maintenance outage decisions and short-term security-constrained scheduling in smart distribution systems," Applied Energy, vol. 96, pp. 281-291, 8// 2012.

[18] T. Sousa, H. Morais, J. Soares, and Z. Vale, "Day-ahead resource scheduling in smart grids considering Vehicle-to-Grid and network constraints," Applied Energy, vol. 96, pp. 183-193, 2012.

[19] M. A. Fotouhi Ghazvini, B. Canizes, Z. Vale, and H. Morais, "Stochastic short-term maintenance scheduling of GENCOs in an oligopolistic electricity market," Applied Energy, vol. 101, pp. 667-677, 2013.

[20] L. Baringo and A. J. Conejo, "Risk-Constrained Multi-Stage Wind Power Investment," Power Systems, IEEE Transactions on, vol. 28, pp. 401-411, 2013.

[21] P. Subcommittee, "IEEE reliability test system," Power Apparatus and Systems, IEEE Transactions on, pp. 2047-2054, 1979.

[22] General Algebraic Modeling System (GAMS). Available: http://www.gams.com 